\title{
A PRODUÇÃO DO CONHECIMENTO NA EDUCAÇÃO FÍSICA BRASILEIRA E A REVISTA BRASILEIRA DE CIÊNCIAS DO ESPORTE
}

\author{
Profa. Dra. Maria Isabel Brandão de Souza Mendes \\ Docente do IFRN. Pesquisadora do GEPEC da UFRN e da Rede \\ CEDES/IFRN. Email: isabelbsm1@gmail.com
}

\begin{abstract}
RESUMO
Visto que a atividade epistemológica é necessária para qualquer área do conhecimento e que sempre está aberta à novas interrogações, o objetivo desse artigo é tecer reflexões sobre publicações da Revista Brasileira de Ciências do Esporte (1979-2003), mais especificamente sobre os conceitos de corpo e saúde e estabelecer relações com as práticas educativas na Educação Física. Diante das discussões apresentadas destacamos que a Educação Física, a partir de meados da década de 80 passa a organizar o conhecimento de modo plural, mas o que prevalece é a polarização das abordagens biológica e histórico-social, o que colabora com a disputa entre elas. Apesar do início de diálogo entre os referenciais das ciências humanas e das ciências naturais, compreendemos que um dos desafios para a área é organizar o conhecimento com base numa racionalidade ampliada que favoreça o diálogo com diferentes lógicas de compreensão, sem favorecer a hierarquização de qualquer tipo de conhecimento. Além da possibilidade dos conceitos se materializarem em práticas educativas, quando estes são incorporados, identificamos que várias práticas educativas que não estão em sintonia com algum tipo de discurso; que oferecem resistência a ele e propiciam outras condições para a emergência de novas regras favorecendo a reorganização de conceitos e a construção de novos discursos.
\end{abstract}

PALAVRAS-CHAVE: Educação Física, Epistemologia, Conhecimento.

\section{THE PRODUCTION OF KNOWLEDGE IN BRAZILIAN PHYSICAL EDUCATION AND BRAZILIAN JOURNAL OF SCIENCE OF SPORT}

\begin{abstract}
Considering that the epistemological activity is necessary to any area of knowledge and also that it is always open to new interrogations, the aim of this paper is to propose some reflections about publications of the Revista Brasileira de Ciências do Esporte (1979-2003), more specifically on body and health concepts, and to establish relationships with education practices in Educação Física. Before the discussion presented, we point out that Educação Física, from the middle of the eighties begins to organize knowledge in a plural way. On the other hand, what prevails is the polarization of biological and historical-social approaches, which collaborates with the dispute between them. In spite of the beginning of the dialog between the referential areas of human sciences and natural sciences, we come to the comprehension that one of the challenges to the area is to organize knowledge based on an amplified rationality which favors the dialog with different comprehension logic, without favoring the hierarch of any kind of knowledge. Besides the possibility of the concepts to materialize in education practices, when they are incorporated, we realize that several education practices which are not in harmony with some kind of speech; that offer resistance to it, provide other conditions to the emergence of new rules which favor the reorganization of concepts and the construction of new speeches.
\end{abstract}

Keywords: Physical Education, Epistemology, Knowledge. 


\section{A PRODUÇÃO DO CONHECIMENTO NA EDUCAÇÃO FÍSICA BRASILEIRA E A REVISTA BRASILEIRA DE CIÊNCIAS DO ESPORTE}

A temática, da produção do conhecimento na Educação Física brasileira é ampla e é abordada pelos pesquisadores da área que se preocupam com a atividade epistemológica, ou seja, se preocupam em interrogar os fatores sociais, culturais, ideológicos e políticos que estão imbuídos nos fundamentos de cada área específica, como destaca Fensterseifer (1999).

No âmbito da atividade epistemológica, nos deparamos com a revisão de conceitos, métodos, problemáticas de investigação, corpo de conhecimento que definem determinada área, relação entre os diversos saberes, limites do próprio conhecimento, linguagem, dentre outros questionamentos.

Não posso deixar de citar alguns estudos recentes que alimentam esse debate. Como o livro de Valter Bracht (1999), denominado "Educação física e ciência: cenas de um casamento (in)feliz”. O livro de Paulo Fensterseifer (2001), intitulado “A educação física na crise da modernidade”. O livro organizado por Amarílio Ferreira Neto (2005), "Leituras da natureza científica do Colégio Brasileiro de Ciências do Esporte" e o livro organizado por Terezinha Petrucia da Nóbrega (2006): "Epistemologia, saberes e práticas da educação física”, fruto do I Colóquio Brasileiro sobre Epistemologia e Educação Física, que foi realizado na Universidade Federal do Rio Grande do Norte, dentre outras.

Visto a diversidade de publicações e reconhecendo então, que a atividade epistemológica é necessária para qualquer área do conhecimento e que sempre está aberta à novas interrogações, me dirijo então para interrogar a Revista Brasileira de Ciências do Esporte (RBCE). Isso ocorre, pelo fato da RBCE ser uma publicação do Colégio Brasileiro de Ciências do Esporte (CBCE), que em setembro de 2008 completa 30 anos, e é considerado como principal entidade científica do Brasil que congrega pesquisadores, profissionais e estudantes de diferentes áreas do conhecimento relacionadas à Educação Física.

Direciono-me, então, para os artigos publicados na RBCE digitalizada (1979-2003) que contribuem com as reflexões sobre os conceitos de corpo e saúde e estabeleço relações com as práticas educativas na Educação Física. Cabe aqui destacar que a necessidade de um recorte, também contribui com as reflexões sobre o todo, se pensarmos como Molina Neto (2005), quando diz que cada parte mantém sua singularidade, mas de algum modo, abarca o todo.

A escolha pelos conceitos de corpo e saúde foi intencional, por compreender que estes conceitos permeiam essa área desde o final do século XIX e início do XX até a contemporaneidade, atravessando-a de ponta a ponta e sofrendo reformulações, rupturas e continuidades ${ }^{1}$.

\footnotetext{
${ }^{1}$ Esse artigo está baseado em pesquisa publicada no livro: MENDES, M. I. B. S. Mens Sana in Corpore Sano: saberes e práticas educativas sobre corpo e saúde. Porto Alegre: Sulina, 2007. Para maiores detalhes sobre a pesquisa consultar o livro.
} 


\section{TECENDO REFLEXÕES SOBRE A REVISTA BRASILEIRA DE CIÊNCIAS DO ESPORTE}

É importante destacar que até meados da década de 1980, a produção do conhecimento da Educação Física era muito influenciada pela área médica, basta ver que até esse período o CBCE era presidido por médicos. Além do Plano Nacional de Educação Física compreender o esporte como solução dos problemas nacionais, esse era um período em que foram implantados laboratórios de fisiologia em diversas universidades do país e as pesquisas realizadas estavam atreladas a eles. A preocupação principal era descobrir atletas e desenvolver suas potencialidades, numa época em que o esporte e a Educação Física eram vistos como possibilidade de aglutinação social num período de ditadura.

Podemos dizer, pelos artigos analisados da RBCE, que até meados da década de 80 do século $\mathrm{XX}$, os conceitos de corpo e saúde se pautam nos referenciais das Ciências Biomédicas e estão vinculados à busca pela boa forma. Prioriza-se o corpo fracionado, medido por partes, e exposto a quantificações, condição principal para a obtenção do conhecimento científico. Os estudos antropométricos se consolidam e a análise do somatotipo serve para classificar as pessoas de acordo com suas características físicas. Os atletas eram modelos para os outros corpos.

Os artigos analisados nesse período estão embasados na idéia de um corpo padronizado, produtor de energia e de trabalho muscular. Um corpo direcionado para aumentar o rendimento, a performance, através do acréscimo de esforço e visualizado a partir dos aspectos anatômicos, fisiológicos, bioquímicos e psicológicos.

Nesse cenário epistemológico em que a comunidade científica está comprometida principalmente com o esporte de alto rendimento, a imagem do atleta contribui com a associação da saúde à juventude. O que impera, é a preocupação com os atletas, diante dos esforços considerados necessários para ampliar o desempenho esportivo. Esse modelo serve de guia para quem não é atleta e a ênfase nas pesquisas é a de justificar os benefícios dos exercícios físicos diante dos treinamentos.

A saúde é reconhecida como ausência de doenças. Ter saúde significava possuir capacidade cardiorrespiratória e composição corporal adequada para agüentar os treinamentos esportivos. Significava resistir fisiologicamente e psicologicamente aos esforços prolongados.

O conceito de saúde se entrelaça com o conceito de estética dentro de uma visão reducionista, entendida, como um padrão único de beleza e está relacionado à boa forma. Busca-se um baixo teor de gordura, responsável por um desempenho atlético considerado ideal.

Nesse contexto, observamos que os laboratórios de fisiologia, principais responsáveis pelas pesquisas produzidas, contribuem com a prática do professor de Educação Física. Essas práticas educativas que trabalham com o esporte de alto rendimento visam o aprimoramento da performance esportiva e são modelos para outros cenários educativos, inclusive na escola.

Preocupa-se em aumentar a capacidade de remover o lactato do sangue e produzir energia; melhorar a função cardiovascular, reduzir o tecido adiposo e evitar a imobilidade, designada como sedentarismo. Busca-se ampliar a potência aeróbica e 
anaeróbica; adequar a freqüência cardíaca conforme o nível do treinamento a alcançar; proporcionar adaptação a esforços prolongados; diminuir a pressão arterial; especializar as habilidades técnicas e a força muscular.

Essas práticas educativas objetivam produzir benefícios fisiológicos e psicológicos sem se preocupar com a reflexão sobre as atividades desenvolvidas. Essa busca pelo talento esportivo fundamenta-se na pedagogia tecnicista. As avaliações realizadas favorecem a comparação do rendimento e o processo seletivo, dirigindo-se à determinação do somatotipo considerado ideal para cada esporte. Além de ser modelo para a educação básica e universitária, o treinamento esportivo colaborou com a emergência na Educação Física em atender também os cardíacos, os diabéticos, dentre outros. As preocupações voltavam-se, entretanto, para a reabilitação, como podemos observar nos artigos analisados.

Ao mesmo tempo, em que se inicia uma preocupação com as pessoas que anteriormente eram denominadas como anormais, doentes, com o objetivo de reabilitá-las, a Educação Física contribuiu primordialmente com uma educação normalizadora, classificatória e excludente e na compreensão de que promove saúde, mesmo que tenha surgido transgressões a essas práticas educativas, como podemos visualizar no estudo de Marco Aurélio Taborda de Oliveira (2004), sobre a história da Educação Física, ao entrevistar alguns professores de EF que atuavam na escola no período de 1968 a 1984 e identificar algumas resistências ao que era hegemônico.

Essas compreensões de corpo e saúde vinculados à boa forma são ressignificadas na década de 90 do século XX. Nesse cenário epistemológico, o método do somatotipo ainda aparece nos artigos analisados, mas emerge, o Índice de Massa Corporal (IMC) para determinar a gordura corporal. Não se busca mais o modelo atlético e sim um estilo de vida ativa idealizado e persegue-se o peso corporal ideal.

Porém, juntamente à essas compreensões expostas anteriormente, surgem também discursos que as problematizam, a partir de meados da década de 80 do século XX e principalmente a partir da década de 90, amparadas fundamentalmente pelos referenciais das Ciências Humanas.

É curioso notar que a partir de 1986 principia um processo de mudanças radicais no CBCE. A direção deixa de ser composta por um médico e passa a ser de professores de Educação Física. As indagações que surgem na RBCE são variadas.

Nesse espaço de indagações ao ideal de cientificidade que sustenta a perspectiva biologicista, a comunidade científica interroga o entendimento da Ciência como mera quantificação e descrição de dados, a neutralidade da Ciência, o reducionismo da Ciência a uma única abordagem metodológica, a empírico-analítica, a fixidez da Educação Física em um único campo de análise, o anátomo-fisiológico, e o ser humano estar relacionado a uma única dimensão, a biológica.

Percebemos que os questionamentos aos conceitos de corpo e saúde e as práticas educativas que consideramos estarem relacionados à perspectiva biologicista, emergem num cenário epistemológico em que os pesquisadores que publicam artigos na RBCE problematizam um ideal de cientificidade relacionado essencialmente à máthêsis, termo utilizado por Michel Foucault (2002), no livro “As palavras e as coisas”. 
Foucault (2002) diz, que quando as pesquisas se reduzem aos valores aritméticos, se pautam em comparações da ordem e da medida e o conhecimento científico é organizado com base no racionalismo. Esse projeto de uma ciência da ordem foi fundado no século XVII e o rigor científico caracteriza-se pela redução da complexidade do fenômeno, observando-se o que é mais simples. A comparação é utilizada no intuito de alcançar a certeza perfeita e erguer juízos perfeitos. Nesse sentido, o saber mantém relação com a máthêsis, ou seja, com a ciência universal da medida e da ordem e o conhecimento busca a possibilidade de estabelecer entre as coisas, uma sucessão ordenada.

Nesse contexto de problematizações à perspectiva biologicista que emerge a partir de meados da década de 80 do século XX, as críticas à compreensão de corpo, pautada no pensamento clássico são diversas. Referem-se aos dualismos e reducionismos, à determinação de padrões corporais, à compreensão de que o corpo é somente um objeto, uma máquina que está isolada do mundo em que vive; dentre outras.

Com vistas a se contrapor à compreensão de corpo, pautada no pensamento clássico, aparecem então na RBCE, a compreensão fenomenológica de corpo, o conceito de corporeidade e a compreensão de corpo da tradição oriental. Além dos aspectos orgânicos, os aspectos culturais, sociais e históricos do corpo humano passam a ser considerado, desvelando os aspectos simbólicos, a capacidade do ser humano se expressar, se comunicar, de atribuir sentidos e de se transformar.

A fundamentação científica que sustenta o esporte somente como produtor de benefícios é posta em questionamento pela idéia de que o esporte também pode provocar malefícios ao ser humano, em especial, nos excessos de treinamento e na especialização precoce.

Aparecem também na RBCE discursos que buscam superar os aspectos individualistas das compreensões de saúde e sua ideologização ao tecerem críticas aos conceitos de saúde como ausência de saúde, como mercadoria e como estado de completo bem estar físico, mental e social, proposto pela Organização Mundial da Saúde em 1948.

Esses discursos enfatizam os aspectos econômicos, sociais, culturais e históricos da saúde. Habitação, alimentação, acesso à escolarização, trabalho, serviços de saúde, transporte, usufruto de tempo livre e liberdade são defendidos como condições de aquisição da saúde e acesso à uma vida digna. A saúde é considerada como o resultado das formas de se organizar socialmente a produção, reconhecidas como geradoras de desigualdades sociais. Começa ainda a emergir nesse periódico, compreensões de saúde que consideram ambos os aspectos e a compreensão existencial de saúde começa a ser referenciada.

Através desses discursos percebemos que as práticas educativas da Educação Física, que buscam eficiência, produtividade e colaboram com a lógica da exclusão são refutadas. $\mathrm{O}$ que se critica são os objetivos da Educação Física escolar, por terem como modelo, o esporte de alto rendimento.

Diante de tantas discussões, percebemos que a Educação Física não se restringe ao aprimoramento da performance esportiva e além dos esportes, a Educação Física na escola possui outros conteúdos, como os jogos, as danças, as lutas e as ginásticas. Podemos perceber que esses discursos destacam ainda a necessidade de se ampliar os objetivos da Educação Física na escola, abrindo espaço para a ludicidade, a criação e o 
prazer. Ao problematizarem a busca por padrões ideais de corpo, reconhecem as possibilidades de se expressar e se comunicar, o heterogêneo e a diversidade cultural. Há ainda uma ênfase nos aspectos políticos e éticos da educação e começa a emergir a necessidade de valorização das subjetividades.

Pelos artigos analisados percebemos que as práticas educativas são orientadas para colaborar com a transformação social, com a superação das desigualdades econômicas e sociais, se preocupam com a formação de valores e com a aceitação da diversidade. Ao enfatizarem uma educação crítica e autônoma, destacam-se as pedagogias críticas da Educação Física na RBCE.

\section{TECENDO CONSIDERAÇÕES}

Diante dos artigos analisados na pesquisa, percebemos uma pluralidade de discursos construídos historicamente, apropriados e reorganizados pela Educação Física na produção científica da área. Uma produção dinâmica permeada por inquietações de pesquisadores que contribuem com o mapeamento do conhecimento produzido na Educação Física brasileira a partir dos registros da RBCE.

Pelo que podemos observar através da análise desses artigos, a Educação Física, a partir de meados da década de 80 do século XX, problematiza uma racionalidade que priorizava o rigor da quantificação e das medições, cujo conhecimento científico organizava-se com base no racionalismo e ocorre um processo de retraimento da mathésis, ou seja, passa-se a controlar e limitar a aplicação das matemáticas.

Observamos então, descontinuidades na ordenação do conhecimento da Educação Física. Os sistemas de pensamento deixam de ser hegemônicos e além das pesquisas realizadas com base nas ciências biomédicas, também existem pesquisas pautadas nas ciências humanas. As descontinuidades, para Michel Foucault (2002), estão relacionadas às mudanças que ocorrem na produção de conhecimento de determinado saber e colaboram com a alteração de sua ordem.

A Educação Física, a partir de meados da década de 80 passa a organizar o conhecimento de modo plural, mas o que prevalece é a polarização das abordagens biológica e histórico-social, o que colabora com a disputa entre elas.

Apesar de identificamos um início de diálogo entre os referenciais das ciências humanas e das ciências naturais, compreendemos que um dos desafios para a área é organizar o conhecimento com base numa racionalidade ampliada que favoreça o diálogo com diferentes lógicas de compreensão, sem favorecer a hierarquização de qualquer tipo de conhecimento.

É interessante perceber, após essas reflexões, que há um entrelaçamento entre os conceitos e as práticas educativas da Educação Física. Essas reflexões sobre os conceitos de corpo e saúde, nos fazem compreender que na Educação Física, as áreas pedagógica, acadêmica e profissional estão entrelaçadas. As práticas de intervenção nos diversos cenários educativos estão relacionadas com a produção do conhecimento da área, através de uma lógica circular e não linear.

Nessa dinamicidade da produção do conhecimento da Educação Física brasileira, identificamos através da análise de artigos da RBCE, condições de possibilidade dos conceitos se materializarem em práticas educativas, quando estes são incorporados. 
Como cita Nóbrega em sua tese de doutorado publicada em 99, os conceitos, "não são apenas nomes que se dão a algo, mas contém uma reflexão e muitas vezes, uma experimentação e uma vivência que lhes dão sentido” (NÓBREGA, 1999, p. 25)

Não podemos também deixar de ressaltar que várias práticas educativas que não estão em sintonia com algum tipo de discurso; que oferecem resistência à ele, propiciam outras condições para a emergência de novas regras que favorecem a reorganização de conceitos e a construção de novos discursos.

\section{REFERÊNCIAS}

BRACHT, Valter. Educação física \& ciência: cenas de um casamento (in)feliz. Ijuí:Unijuí, 1999.

FENSTERSEIFER, Paulo Evaldo. Conhecimento, epistemologia e intervenção. IN: GOELLNER, S. V. Educação Física/Ciências do Esporte: intervenção e conhecimento. Florianópolis: Colégio Brasileiro de Ciências do Esporte, 1999.

A educação física na crise da modernidade. Ijuí: Unijuí, 2001. ]

FERREIRA NETO, Amarílio (Org.). Leituras da natureza científica do Colégio Brasileiro de Ciências do Esporte. Campinas: Autores Associados, 2005.

FOUCAULT, Michel. As palavras e as coisas: uma arqueologia das ciências humanas. Tradução de Salma Tannus Muchail. São Paulo: Martins Fontes, 2002.

MENDES, M. I. B. S. Mens Sana in Corpore Sano: saberes e práticas educativas sobre corpo e saúde. Porto Alegre: Sulina, 2007.

MOLINA NETO, Vicente et al. A produção do conhecimento em Educação Física e Ciências do Esporte: campos e métodos. IN: XIV Congresso Brasileiro de Ciências do Esporte / I Congresso Internacional de Ciências do Esporte. Anais. Porto Alegre: UFRGS, 2005.

NÓBREGA, Terezinha Petrucia. Para uma teoria da corporeidade: um diálogo com Merleau-Ponty e o pensamento complexo. 219f. Tese (Doutorado em Educação). Unimep, Piracicaba, 1999.

(Org.). Epistemologia, saberes e práticas da educação física. João Pessoa: Editora Universitária / UFPB, 2006.

OLIVEIRA, Marcus Aurélio T. Educação física escolar e ditadura militar no Brasil (1968-1984): entre a adesão e a resistência. Revista Brasileira de Ciências do Esporte. V.25, n. 2, p. 9-20, jan. 2004. 